\title{
Strength Analysis and Structure Optimization of Gate Valve Body Based on Finite Element Software
}

\author{
Xiaoke He ${ }^{1,2}$, Chenjun Zhang ${ }^{3, *}$, and Ding Tian ${ }^{1}$ \\ ${ }^{1}$ School of electric power, North China University of Water Resources and Electric Power, 450045, China \\ ${ }^{2}$ Farmland Irrigation Research Institute, CAAS/ Key Laboratory of Water-Saving Agriculture of Henan Province, 453002, China \\ ${ }^{3}$ School of Mechanical Engineering, Luoyang Institute of Science and Technology, 471023, China
}

\begin{abstract}
Stress concentration zone and maximum deformation zone of gate valve at $1.6 \mathrm{MPa}$ working pressure were found out according to strength calculation and analysis by ANSYS software, which proceeds the processes of modeling, meshing, constraints define, applying loads and solving. Design variables, state variables and optimize targets were defined by target optimization design function of ANSYS Workbench in order to reveal the influence law of each design variable on the gate valve body equivalent stress, and the optimal values of design variables could be obtained after calculation. The valve structure was improved and stress concentration was reduced from the perspective of safety and economy, which could provide a reference for reliable valve design. The shape of the valve body was optimized by topology optimization design in order to achieve the rational use of materials. Research results show that the maximum stress lies on both sides of the valve rib plate and the stress is beyond the material allowable value, but the valve body has little deformation. After optimization the maximum equivalent stress of valve body is decreased by $23.91 \%$ and the valve body has uniform stress distribution, the mass of the valve body is reduced by $1.4 \%$ as well. Material utilization is improved effectively, which indicates that the optimization design based on ANSYS Workbench is highly efficient and reliable.
\end{abstract}

\section{Introduction}

Gate valve is one of the most widely used valves during industrial production, which plays an important role in agriculture irrigation, nuclear energy field, aerospace, petrochemical, machinery, pharmaceutical and other industrial departments. According to statistics, the number of gate valves accounts for $70 \%$ of the total valves number in the chemical sector [1]. During original valves design, the three-dimensional models were mainly set up by artificial way, and every node equation was solved after meshing process according to the valve model characteristics, in which way the various aspects factors of the valve were analyzed [2-3]. However, this kind of design method was proved to be useless as its heavy workload, complicated calculation process, and low calculation accuracy. What's more, local stress concentration and unreasonable stress distribution always appeared due to the structural reason of gate valve during practical application.

With the development of computer technology and mechanical theory, the three dimensional mechanics analysis of structure through finite element analysis method provided by CAE software is becoming mature and widely used in structure analysis of pressure vessels [4]. CAD/CAE function provided by ANSYS software could play a positive role in the process of the gate valves modeling and finite element analysis, thus realizes size and structure optimization of gate valves. This method could improve the valve structural design level, reduce the valve design cycle and manufacturing cost, which affords reliable improvements for valves design.

A certain type gate valve with $700 \mathrm{~mm}$ nominal diameter and $1.6 \mathrm{MPa}$ rated working pressure was analyzed by ANSYS software in this paper. Whether the valve body could survive stable pressure without apparent elastic-plastic deformation under the condition of hydrostatic test is mainly considered, the structure under strong stress was optimally designed to ensure the gate valve body reliability and reasonable use of materials.

\section{Material and Methods}

\subsection{Modeling}

Parametric model of the valve body should be able to accurately reflect the actual situation of the structure [5-7], that is to say, its shape, boundary conditions and loads should keep consistent with actual situation. The model should be simplified as much as possible on the premise of guarantee calculation precision, therefore those characteristics which do not affect the valve body overall performance can be simplified in the process of

\footnotetext{
${ }^{*}$ Corresponding author: 532215216@qq.com
} 
modeling. After ignore some unnecessary chamfering, parametric calculation model of gate valve is obtained as shown in Figure 1 [8-10].

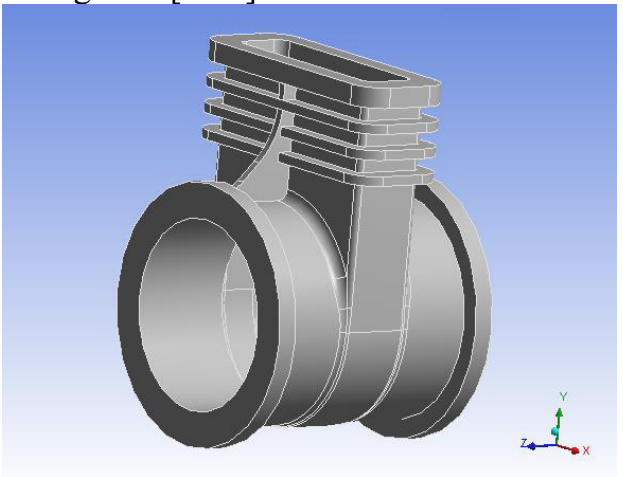

Fig. 1. Parametric calculation model of gate valve.

\subsection{Mesh generation}

The quality of finite element meshing directly affects the reliability of analysis results and the time cost of analysis process [11-12]. As the valve body has irregular shape, we mesh the model with 10 nodes tetrahedron element in order to make calculation results more accurate, and the grid of mutation valve shape is encrypted. Mesh generation of the valve model is shown in Figure 2.

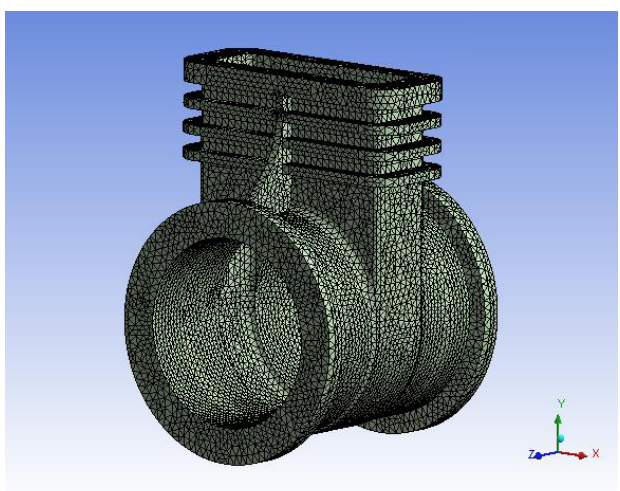

Fig. 2. Mesh generation.

\subsection{Applying constraints and loads}

Fixed constraint is applied on both end faces of the valve body import and export flange, and vertical constraint is applied on the end face of middle flange. According to the requirements of valve hydraulic pressure test, $2.4 \mathrm{MPa}$ calculation pressure is applied on the valve body inside surface, the bolt retightening force of middle flange and the weight of valve are ignored.

\subsection{Define material}

The material of gate valve body is WCB (Workmen's Compensation Board), and the material characteristics are shown in Table 1.

Table 1. Material characteristics of gate valve body.

\begin{tabular}{cccccc}
\hline Name & $\begin{array}{c}\text { Elasticity } \\
\text { modulus }\end{array}$ & $\begin{array}{c}\text { Poisson } \\
\text { ratio }\end{array}$ & $\begin{array}{c}\text { Extension } \\
\text { strength }\end{array}$ & $\begin{array}{c}\text { Yield } \\
\text { strength }\end{array}$ & $\begin{array}{c}\text { Allowable } \\
\text { stress }\end{array}$ \\
\hline Symbol/Unit & $E / \mathrm{GPa}$ & $\mu$ & $\sigma_{b} / \mathrm{MPa}$ & $\sigma_{s} / \mathrm{MPa}$ & {$[\sigma] / \mathrm{MPa}$} \\
Value & 206 & 0.25 & 482.8 & 248.3 & 120.69
\end{tabular}

\section{Results}

The deformation and equivalent stress nephogram of gate valve body which obtained after calculation are shown in Figure 3. The maximum deformation of valve body is $0.41 \mathrm{~mm}$ under $2.4 \mathrm{MPa}$ test pressure. During the original valve design the valve body deformation is controlled under the range of 0.001 times of nominal diameter to protect mechanical seal, that is to say, the gate valve with $700 \mathrm{~mm}$ nominal diameter has $0.7 \mathrm{~mm}$ allowable deformation [13-14]. From Figure 3(a) we can see that the designed valve body meet stiffness requirement. But in Figure 3(b) we can see that the maximum stress on both sides of the valve body floor is $149.6 \mathrm{MPa}$, which is beyond the allowable stress of the valve body material. From the calculation results it can be concluded that the valve cannot meet work requirements. Consequently, the sizes of both sides of valve body floor should be optimal designed from the view of safety and economy in order to reduce the stress concentration phenomenon and ensure the valve body strength.

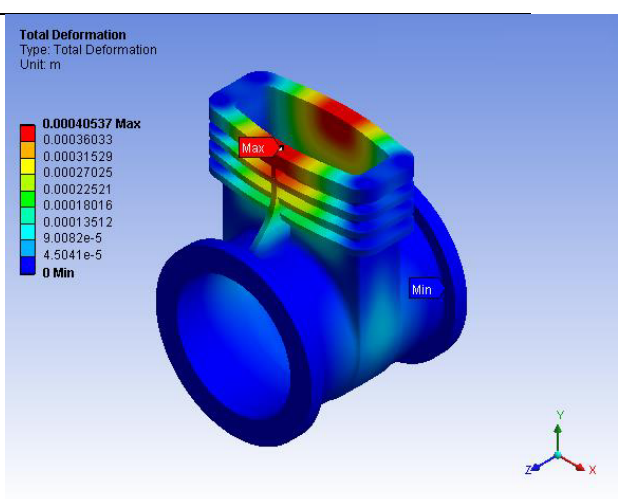

(a) Total deformation nephogram 


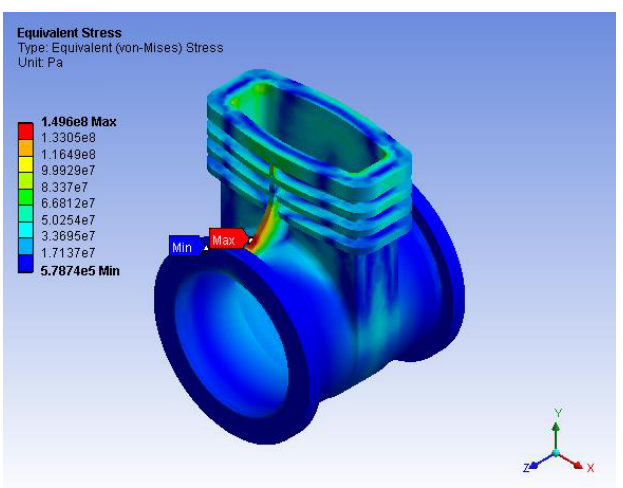

(b) Equivalent stress nephogram

Fig. 3. Deformation and equivalent stress nephogram of valve body.

\section{Discussion}

\subsection{Structure parameters which affect the valve body strength}

From Figure 3(b) we can see that the maximum stress lay on the both sides of valve body floor, in other words, shape of the valve body floor have great influence on the valve body strength. During optimal design we mainly consider the sizes of valve body floor, define the floor thickness as D, and define the floor bottom chamfer as R. There are totally two structure parameters that influence the body strength are defined as design variables in this paper.

\subsection{Valve structure parameters optimization}

In order to make the valve body has uniform stress distribution and meet the strength requirements, the valve structure optimal design aim to make the maximum equivalent stress as small as possible under the constraint of valve weight, $D$ and $R$ as design variables at the same time. Optimize target is to make the maximum equivalent stress of valve body as small as possible, which is less than the material allowable stress $120.69 \mathrm{MPa}$. The valve weight is set as state variable, which is ensured to be as small as possible during the optimization process. According to the needs of the practical operation, the range of design variables is determined as shown in Table 2.

Table 2. The range of design variables.

\begin{tabular}{cccc}
\hline $\begin{array}{c}\text { Design } \\
\text { variables }\end{array}$ & Minimum $/ \mathrm{mm}$ & Maximum $/ \mathrm{mm}$ & Initial $/ \mathrm{mm}$ \\
\hline $\mathrm{D}$ & 10 & 30 & 15 \\
$\mathrm{R}$ & 80 & 400 & 100
\end{tabular}

The optimization program is operated automatically, and the mesh of the model is redistributed in each optimization circulation till the optimization finished.

\subsection{The influence of design parameters to equivalent stress}

The response diagrams are obtained from DesignXplorer optimization module of ANSYS Workbench, and the influence of parameter $\mathrm{D}$ to valve body equivalent stress is shown in Figure 4(a). We can see that equivalent stress reach the maximum value when the floor thickness is 22 $\mathrm{mm}$, and the stress decreases with the increase of the floor thickness when $\mathrm{D}$ is greater than this value. The maximum equivalent stress is less than $120 \mathrm{MPa}$ when D reaches to $29 \mathrm{~mm}$. The influence of parameter $R$ to valve body equivalent stress is shown in Figure 4(b), obviously, the equivalent stress decreases with the increase of $\mathrm{R}$. Combined influence of $\mathrm{D}$ and $\mathrm{R}$ to valve body equivalent stress is shown in Figure 5.

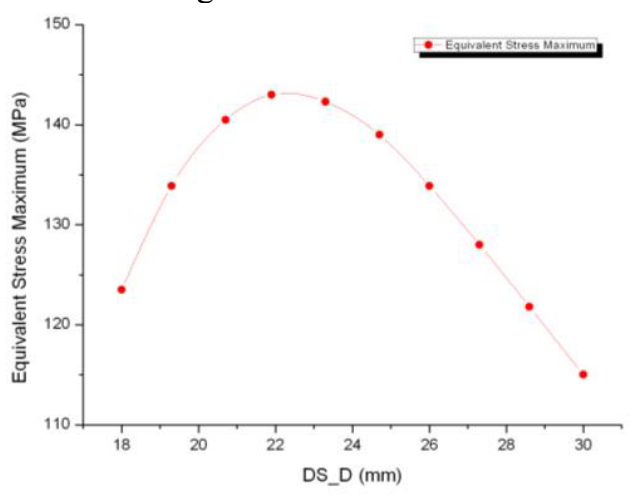

(a) Parameter D

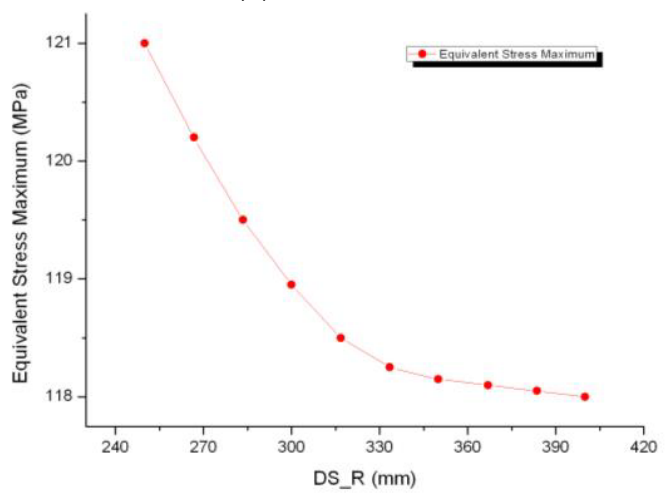

(b) Parameter $\mathrm{R}$

Fig. 4. Influence of parameters D and R to valve body equivalent stress.

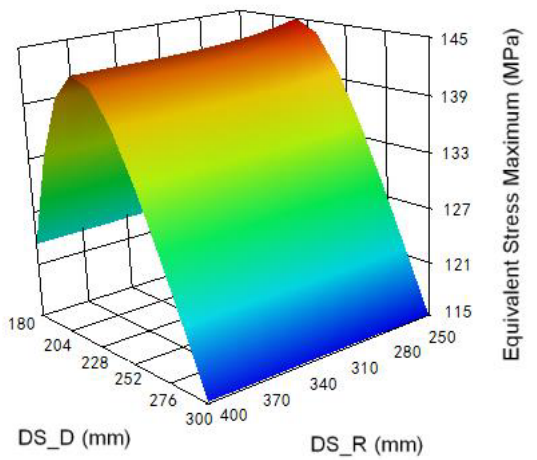

Fig. 5. Combined influence of parameters $D$ and $R$ to valve body equivalent stress. 


\subsection{Optimization results and analysis}

After optimization analysis of valve body structure parameters, we get optimization results of parameters D and $\mathrm{R}$ which is shown in Table 3.

Table 3. Optimization results comparison.

\begin{tabular}{ccc}
\hline $\begin{array}{c}\text { Design } \\
\text { variables }\end{array}$ & $\begin{array}{c}\text { Before } \\
\text { optimization } / \mathrm{mm}\end{array}$ & $\begin{array}{c}\text { After } \\
\text { optimization } / \mathrm{mm}\end{array}$ \\
\hline $\mathrm{D}$ & 15 & 29 \\
$\mathrm{R}$ & 100 & 367 \\
\hline
\end{tabular}

The improved model with optimized $\mathrm{D}$ and $\mathrm{R}$ is analyzed, and calculation results are shown in Figure 6. The maximum equivalent stress point of valve body moved to the intersection of rib plate and middle flange. The maximum stress value is $113.83 \mathrm{MPa}$, which is decreased by $23.91 \%$. The maximum deformation is $0.32 \mathrm{~mm}$, decreased by $21.95 \%$, which indicates that both strength and stiffness of the improved valve meet work requirements.

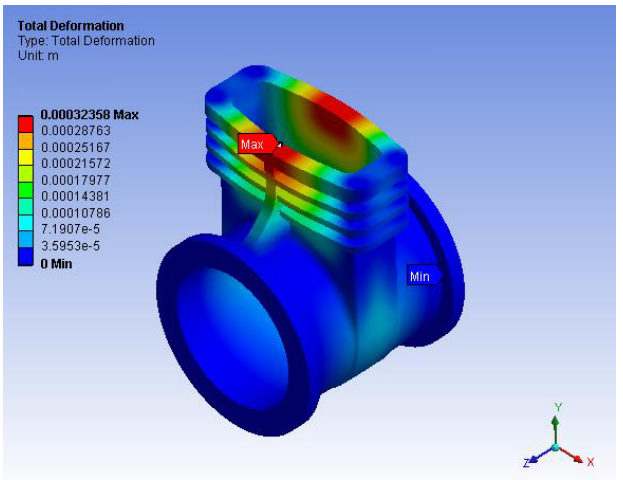

(a) Total deformation nephogram

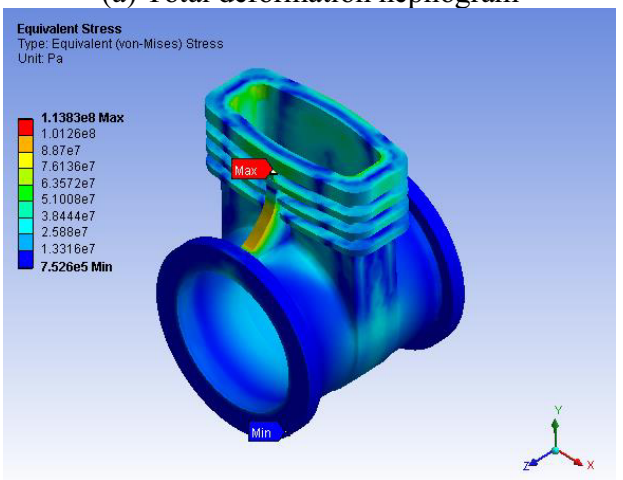

(b) Equivalent stress nephogram

Fig. 6. Deformation and equivalent stress nephogram of gate valve after optimization.

\subsection{Topology optimization design of valve structure}

Topology optimization design is actually a kind of model's geometry optimization, sometimes it also can be called layout optimization [15-16]. Target of topology optimization design is to seek the best use solution of material under a given constraints such as saving volume, and a certain target such as total strength or stiffness should be achieved to be maximum or minimum at the same time [17-18].
After comprehensive analysis, the command Shape Optimization of ANSYS Workbench is carried out. Constraints and loads are set the same as the third section of this paper, and target reduction is set as $60 \%$. By carrying out the command Shape Finder we get calculation results as shown in Figure 7(a), Red zones in Figure 7(a) are parts that can be removed. According to the result of topology optimization and considering the processing technology and manufacturing cost, the length of both sides of the valve reinforcing rib is shortened by $40 \mathrm{~mm}$ as shown in Figure 7(b).

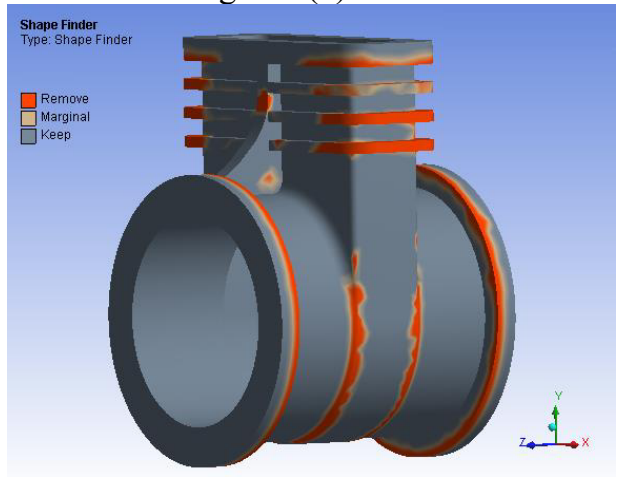

(a) Results of topology optimization

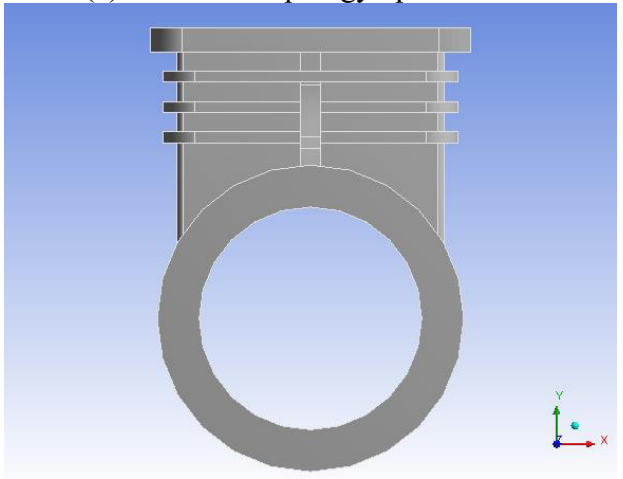

(b) The modified model of valve

Fig. 7. Results of topology optimization and the modified model of valve.

The analysis results of modified valve model are shown in Figure 8. From Figure 8 we can see that the maximum deformation and maximum equivalent stress of modified valve model is tiny, which indicates that strength and stiffness of the modified valve meet design requirements. What's more, total mass of the valve decreases from $1748.4 \mathrm{Kg}$ to $1723.4 \mathrm{Kg}$, which is reduced by $1.4 \%$.

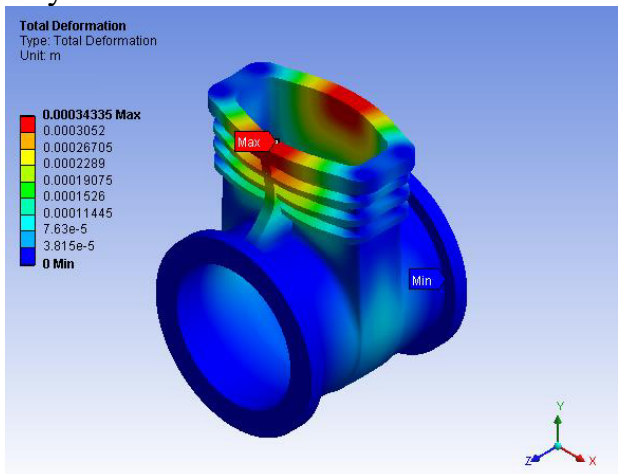

(a) Total deformation nephogram 


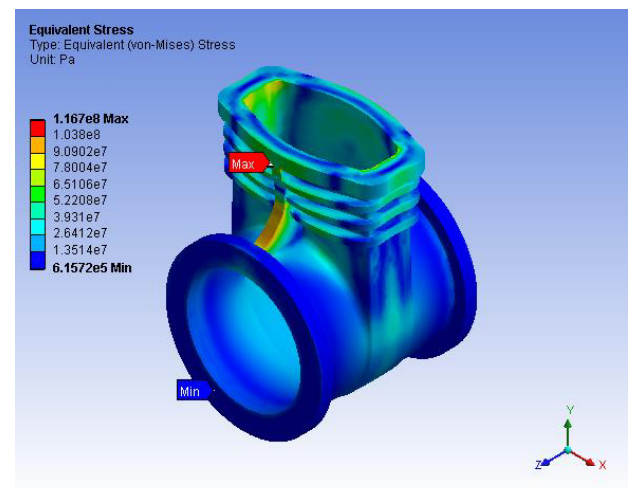

(b) Equivalent stress nephogram

Fig. 8. Deformation and equivalent stress nephogram of gate valve after topology optimization.

\section{Conclusion}

Parameterized model of gate valve is built through ANSYS software in this paper, and deformation and equivalent stress of the valve are finite element analyzed. The structure of the gate valve is improved by parameters optimization analysis and topology optimization analysis, which provide a reference for gate valve design.

(1) Analysis results show that the total strength of the valve body is improved after structural optimization design, the maximum equivalent stress of the improved valve is decreased by $23.91 \%$ with more uniform stress distribution.

(2) Material of the valve body is reduced under the premise of meet the work requirements, material utilization is improved by $1.4 \%$.

(3) The valve design cycle is reduced substantially and design efficiency is enhanced effectively by using this design method, which has high efficiency and accuracy. It can be concluded that finite element analysis is an effective method for valves structural design.

\section{Acknowledgement}

This study was financially supported by the Henan Province Education "The 13th Five-Year Plan" Project of Year 2016 (2016-JKGHA-0017) and the Open Fund of Key Laboratory of Water-saving Agriculture of Henan Province (FIRI2016-19-01).

\section{References}

1. Battini, D., Donzella, G., Avanzini, A., et al. Experimental testing and numerical simulations for life prediction of gate valve O-rings exposed to mixed neutron and gamma fields. Materials \& Design, 156: 514-527. (2018)

2. Lu, P. Introduction and proficiency in valve design. China Machine Press, Beijing. (2013)

3. Li, B., He, Z., Chen, X. ANSYS Workbench design, simulation and optimization. Tsinghua University Press, Beijing. (2013)

4. Han, J. Thermal-structural analysis and fatigue life evaluation of a parallel slide gate valve in accordance with ASME B\&PVC. Transactions of the KSME, 41: 157-164. (2017)

5. Lin, Z., Ma, G., Cui, B., et al. Influence of flashboard location on flow resistance properties and internal features of gate valve under the variable condition. Journal of Natural Gas Science and Engineering, 33: 108-117. (2016)

6. Minhas, A., Patel, S., Kazerooni, E., et al. Iterative reconstruction results in larger computed tomography measurements of iliofemoral artery diameter in patients referred for transcatheter aortic valve replacement. Journal of Computer Assisted Tomography, 40: 773-776. (2016)

7. Hao, W., Noureddine, B., Abdellatif, I., et al. Fracture toughness prediction of a valve body: numerical analysis. Engineering Failure Analysis, 17: 135-142. (2010)

8. Novosel, L., Perkov, D., Dobrota, S., et al. Aortic coarctation associated with aortic valve stenosis and mitral regurgitation in an adult patient: a two-stage approach using a large-diameter stent graft. Annals of Vascular Surgery, 28: 15-20. (2014)

9. Cai, H., Gao, L., Xu, L. Calculation of maximum torque operating conditions for inverter-fed induction machine using Finite-Element Analysis. IEEE Transactions on Industrial Electronics, 66: 2649-2658. (2019)

10. Wang, S., Wang, Y., Zi, Y., et al. A 3D finite element-based model order reduction method for parametric resonance and whirling analysis of anisotropic rotor-bearing systems. Journal of Sound and Vibration, 359: 116-135. (2015)

11. Fertahi, S., Bouhal, T., Arid, A., et al. Thermo-mechanical strength analysis for energy storage improvement of horizontal storage tanks integrating evacuated tube collectors. International Journal of Hydrogen Energy, 42: 29370-29383. (2017)

12. Alonso, D., De, S., Saenz, J., et al. Topology optimization applied to the design of 2D swirl flow devices. Structural and Multidisciplinary Optimization, 58: 2341-2364. (2018)

13. Mahomed, N., Kleynhans, H. Reducing shrinkage porosity in high-performance steel castings: case of an ASME B16.34 gate valve body: Part 1-analysis, techniques and experimental approach. International Journal of Metalcasting, 12: 919-926. (2018)

14. Sumit, D. Stress analysis of gate valve by ANSYS. DAV International Journal of Science, 3: 33-41. (2013)

15. Li, S., Li, L., Hou, Y. Seal analysis and optimization of large diameter gate valve based on ANSYS. Applied Mechanics and Materials, 415: 498-501. (2013)

16. Lin, Z., Zhu, L., Cui, B., et al. Effect of placements (horizontal with vertical) on gas-solid flow and particle impact erosion in gate valve. Journal of 
Thermal Science, 23: 558-563. (2014)

17. Sathishkumar, S., Hemanathan, R., Gopinath, R., et al. Design and analysis of gate valve body and seat ring. International Journal of Mechanical Engineering and Technology, 8: 131-141. (2018)

18. Mahmoodi, K., Ghassemi, H., Nowruzi, H., et al. Prediction of the hydrodynamic performance and cavitation volume of the marine propeller using gene expression programming. Ships and Offshore Structures, 14: 723-736. (2019) 